This document is the accepted manuscript version of the following article:

Wigger, H., Kawecki, D., Nowack, B., \& Adam, V. (2019). Systematic consideration of parameter uncertainty and variability in probabilistic species sensitivity distributions. Integrated Environmental Assessment and Management. https://doi.org/10.1002/ieam.4214

Bernd Nowack ORCID iD: 0000-0002-5676-112X

\title{
Systematic consideration of parameter uncertainty and vari- ability in probabilistic species sensitivity distributions
}

\author{
Henning Wigger, Delphine Kawecki, Bernd Nowack*, Véronique Adam \\ Empa, Swiss Federal Laboratories for Materials Science and Technology, \\ Technology and Society Laboratory, Lerchenfeldstrasse 5, 9014 St. Gallen, \\ Switzerland \\ *Corresponding author: nowack@empa.ch
}

\section{Acknowledgements}

H.W. and V.A. were supported by caLIBRAte which has received funding from the European Union's Horizon 2020 Research and Innovation Programme under Grant Agreement 686239.

\section{Disclaimer}

The authors declare no conflict of interests.

\section{Data Availability Statement}

The simulation framework is available as a software package at https://doi.org/10.5281/zenodo.3267194

\begin{abstract}
The calculation of a species sensitivity distribution (SSD) is a commonly accepted approach to derive the predicted no-effect concentration (PNEC) of a substance in the context of environmental risk assessment. The SSD approach usually is data demanding and incorporates a large number of ecotoxicological values from different experimental studies. The probabilistic SSD (PSSD) approach is able to fully consider the variability between different exposure conditions and material types, which is of great importance when constructing a SSD for any chemical, especially for nanomaterials. The aim of our work was to further develop the PSSD approach by implementing methods to better consider the uncertainty and variability of the input
\end{abstract}

This article is protected by copyright. All rights reserved. 
data. We incorporated probabilistic elements to consider the uncertainty associated with uncertainty factors by using probability distributions instead of single values. The new PSSD method (named PSSD ${ }^{+}$) computes 10'000 PSSDs based on a MonteCarlo routine. For each PSSD calculated, the HC5 was extracted to provide a PNEC distribution based on all data available and their associated uncertainty. The PSSD ${ }^{+}$ approach also includes the option to consider a species weighting according to a typically constituted biome. We applied this PSSD $^{+}$approach to a previously published data set on carbon nanotubes and silver nanoparticles. The evaluation of the uncertainty factor distributions and species weighting have shown that the proposed PSSD method is robust with respect to the calculation of the PNEC value. Furthermore, we demonstrated that the $\operatorname{PSSD}^{+}$can handle both small and more comprehensive datasets as the PNEC distributions are a close representation of the data available. Finally, the sensitivity testing towards data set variations showed that the maximum variation of the mean PNEC was of a factor of about two, so that the method is relatively insensitive to missing data points as long as the most sensitive species is included.

Keywords: species sensitivity distribution, hazard assessment, predicted no-effect concentration, uncertainty

\section{Key points}

We incorporated probabilistic elements in SSDs to consider the uncertainty associated with uncertainty factors by using probability distributions instead of single values and species weighting according to a typical biome.

The HC5 extraction of all calculated PSSDs yields a PNEC distribution based on all data available and their associated uncertainty without omitting data points for species due to data aggregation.

The new PSSD ${ }^{+}$approach avoids the fitting problem of conventional SSDs and can be used for small and bigger datasets.

\section{Introduction}

Environmental and ecological risk assessments of a substance require the comparison of an environmental concentration, which can be measured or predicted, with the predicted no-effect concentration (PNEC). The calculation of a species sensitivity distribution (SSD) is a commonly accepted approach to derive the PNEC of a substance (Monti et al., 2018). Generally, the SSD approach considers several environmental species that are assumed to be representative of the biological community of an environmental compartment. Substance- and compartment-specific data are collected and This article is protected by copyright. All rights reserved. 
evaluated, and a curve is built that adequately fits the data points (Posthuma et al., 2002, Hickey and Craig, 2012). Parametric and non-parametric approaches can be used to fit a curve to the dataset. On the SSD, the sensitivity of the species is represented in a cumulative order depending on the effect concentration associated with each of them. This allows one to determine an environmental concentration that would protect a given percentage of species in a specific compartment. In the European regulatory context, the PNEC value is usually derived from the $\mathrm{HC}_{5}$ (hazardous concentration for $5 \%$ of species), protecting $95 \%$ of the biological community against the stressor in question (Aldenberg and Slob, 1993, Iwasaki et al., 2015, ECHA, 2008). Additionally, an assessment factor of one to five has to be applied to the $\mathrm{HC}_{5}$ to consider the quality of the data set used (ECHA, 2008).

The first crucial step in the SSD approach is the selection of the experimental data. Thereby, the selection of the endpoint tested (e.g. growth, mortality etc.) is key to build a meaningful SSD (Smetanova et al., 2014). The toxicity values are reported in the literature as measures of the effect concentration $\left(\mathrm{EC}_{\mathrm{x}}\right)$, inhibition concentration $\left(\mathrm{IC}_{\mathrm{x}}\right)$ and lethal concentration $\left(\mathrm{LC}_{\mathrm{x}}\right)$ at a certain percentage ' $\mathrm{x}$ ' as well as the lowest observed effect concentration (LOEC) or the no-observed effect concentration (NOEC). Generally, $\mathrm{EC}_{\mathrm{x}}$ or NOECs are preferred to create the SSD. The discussion on which measure is the most adequate is still ongoing (Green et al., 2013, Fox and Landis, 2016). The NOEC was criticized to have no biological meaning since it is not a measure of toxicity, but rather of non-toxicity. The NOEC considerably depends on the study design that can lead to higher variability (Laskowski, 1995, Jager, 2012, Fox and Landis, 2016, Monti et al., 2018, Isnard et al., 2001). Thus, the measure of $\mathrm{EC}_{\mathrm{x}}$ was proposed to replace the NOEC, whilst the selected value for " $\mathrm{x}$ " depends on jurisdiction and risk management objectives (Isnard et al., 2001, Beasley et al., 2015). Still, the NOEC and $\mathrm{EC}_{10}$ represent the conservative values for assessing the PNEC, which are proposed by the European regulation (Monti et al., 2018, ECHA, 2008).

In the European regulatory context, chronic data are preferred over acute datasets, since chronic studies include more life stages of the organisms and are therefore often more representative of their response towards the stressor in the environment (ECHA, 2008). However, acute data are more often available than chronic data and are representative of specific conditions such as pulsed exposures. It is often assumed that if more data are included in the SSD, the results are a better representation of reality, but this representation actually depends highly on the design of the studies included and on the way in which the data are reported (Dowse et al., 2013, Newman et al., 2000). Hence, both the data quantity and quality have to be considered in SSD assessments. Nevertheless, due to prevalent data scarcity, a trade-off between data quality and data quantity has to be made to foster the building of representative SSDs (Dowse et al.,

This article is protected by copyright. All rights reserved. 
2013). To this aim, uncertainty factors (UFs) were proposed to convert acute data to chronic values (also named acute-to-chronic ratios) (Iwasaki et al., 2015, Harmon et al., 2017, Smetanova et al., 2014) and the various dose-descriptors reported (i.e. LOEC, $\mathrm{EC}_{10}, \mathrm{EC}_{25}, \mathrm{EC}_{50}$ etc.) to NOEC or $\mathrm{EC}_{\mathrm{x}}$. Some UFs are generally recommended by the European regulation (ECHA, 2008) even though they can vary depending on the species and substances. The SSDs can then be calculated based on empirically derived chronic data combined with chronic data derived from acute datasets to enlarge the overall dataset.

The parametric approaches fit SSDs to the data presuming that the response of biological communities follows a given distribution (e.g. log-normal, log-logistic or Burr type III distribution (Wheeler 2002)). Yet, the biological community does not necessarily follow one single distribution (Xu et al., 2015). Non-parametrical SSD approaches have been developed to tackle this challenge (Newman et al., 2000, Wang et al., 2015, Monti et al., 2018). One of these approaches is the probabilistic species sensitivity distribution (PSSD) (Gottschalk and Nowack, 2013). The PSSD approach addressed the fitting problem by avoiding the use of pre-defined distributions to derive the PSSD with an empirical calculation using the complete dataset. Additionally, the inter-laboratory variability of data points stemming from experiments is considered in the approach. The result was one single PSSD that was representative for the dataset.

The parametric SSD approach includes only one value for each species (e.g. geometrical mean or lowest value) (Belanger et al., 2017), which does not represent the variability of the effect encountered in the whole environmental compartment. Semenzin et al. (2015) proposed to improve the data handling by addressing the species selection bias and data quality problem. These authors introduced weighting factors for data quality, trophic level and species relevance before the actual calculation was performed. However, the main advantage of the PSSD is that it considers the complete variability of all NOECs for each species and does not select only one value among all that are available. It therefore reflects much better the variability of responses that may occur in the environment. This PSSD approach has been applied to several compounds such as nanomaterials (Coll et al., 2016, Wang et al., 2016, Wang and Nowack, 2018, Giese et al., 2018, Wigger and Nowack, 2019).

The aim of this work was to develop further the probabilistic element of the existing PSSD method, providing a fully transparent methodology. By doing so, we have included the uncertainty associated with the UFs and extended the PSSD calculation to several PSSDs, which results in a closer representation of the data than the use of geometric means and more complete representation of their uncertainty than in previous methodologies such as in Gottschalk and Nowack (2013). Additionally, we included a weighting scheme with respect to a typical biological community in the freshwater This article is protected by copyright. All rights reserved. 
compartment to assess the potential influence on the results and show the capability of the probabilistic species sensitivity distribution plus ( $\mathrm{PSSD}^{+}$) approach to include species weighting. Based on these newly implemented probabilistic elements, a probability distribution for the PNEC is derived incorporating all associated uncertainties. The $\mathrm{PSSD}^{+}$was applied to carbon nanotubes (CNT) and nano-Ag from two previously published datasets (Coll et al., 2016), representative for a case with few data (CNT) and one very rich in data (nano-Ag).

\section{Material and methods}

The dataset used and the PSSD ${ }^{+}$approach are described in more detail in this section. It is aligned on the requirements of the Reach guideline R.10 provided by the European Chemical Agency (ECHA, 2008). Particularly, the data collection, the main requirements of the SSD and the application of UFs are described in this guideline, which we have followed as far as possible. Any exceptional deviations from this guideline are transparently discussed where it pertains in this article.

Selection of case studies, data collection and preparation

The datasets used to apply the PSSD ${ }^{+}$method were based on those of Coll et al. (2016), detailed in Tables S1 and S2 of the Supplementary Information (SI). PSSDs were built for both nano-Ag and carbon nanotubes (CNTs). These case studies represent two cases of data availability, which was useful to test the robustness of our method. Many ecotoxicity data are available for nano-Ag while only a limited dataset could be obtained for CNTs.

The data were collected from peer-reviewed studies that characterized changes in reproduction, mortality, growth or any relevant metabolic process (e.g. photosynthetic activity, (ECHA, 2008)). If the study had reported chronic (i.e. long-term) as well as acute values, the first were preferred, while the latter were neglected. In total, 11 species and 24 data points were included in the CNT dataset, while that of nano-Ag contained 26 species and 173 data points. All data points were treated in the same way and combined in the substance-specific PSSDs. All REACH criteria on the occurrence of different types of species were met for nano-Ag, while three of them could not be met for CNTs (cf. Table 1). It has to be noted that we did not check the quality of the data (i.e. the experimental setup) used as this article is merely focused on the development of the method itself. The application of the PSSD+ approach should be accompanied by a detailed analysis of the studies used in the assessment.

Different types of dose descriptors were given in the studies analysed, from $\mathrm{EC}_{\mathrm{x}}$, LOECs, minimum inhibitory concentrations (MICs) to highest observed no effect

This article is protected by copyright. All rights reserved. 
concentrations (HONECs) and NOECs. To comply with REACH guidance R.10 (ECHA, 2008) that recommends to use chronic NOECs or $\mathrm{EC}_{10} \mathrm{~s}$ if possible, all data points were converted into chronic NOECs by applying two UFs, for which uncertainty ranges were attributed (Tables 2 and 3). The first uncertainty factor $\left(U_{t}\right)$ considered the duration of the experiment and was used to convert acute measurements to chronic estimations. The second uncertainty factor $\left(\mathrm{UF}_{\mathrm{dd}}\right)$ was used to convert a specific dose-descriptor to a NOEC. The assumptions and reasoning to derive the modal values of the UFs are shown in Tables 2 and 3. It has to be noted that UFs are critically discussed and no generic agreement is reached so far. Particularly, the conversion of different dose descriptors to obtain a NOEC is not yet regulated. An exception is the derivation of a NOEC based on a LOEC divided by 2 as described in the REACH guideline R.10 (ECHA, 2008). As a starting point for the transformation of $\mathrm{EC} / \mathrm{LC} / \mathrm{IC}_{25}$ to $\mathrm{EC} / \mathrm{LC} / \mathrm{IC}_{50}$, we have selected 10 as the modal value being used in the $\mathrm{PSSD}^{+}$approach. All $\mathrm{UF}_{\mathrm{dd}}$ probability distributions were triangular, with the minimum and maximum values being $50 \%$ and $150 \%$ of the modal value, respectively.

Some acute-to-chronic ratios (or $\mathrm{UF}_{\mathrm{t}}$ ) were calculated in the literature for nano-Ag (Harmon et al., 2017). The authors found values as low as 1.6. This was set as the minimum value of the probability distribution. Acute-to-chronic ratios usually used are 10 , so this was set as the modal value of the probability distribution. To be conservative, we chose a maximum value of 100, which is the order of magnitude of the highest acute-to-chronic ratios calculated for metals (Raimondo et al., 2007). To the best of our knowledge, no acute-to-chronic ratios were reported for CNTs so far. Therefore, we used a triangular probability distribution with a modal value of 10 , a minimum value of 5 (50\% of 10 ) and a maximum value of 150 (150\% of 10$)$. This last probability distribution can be considered as generic, to be used when no more information is available, while the probability distribution for $\mathrm{UF}_{\mathrm{t}}$ of nano-Ag is more specific. Two cases are therefore illustrated in this study, a generic one and a specific one.

The choices of $\mathrm{UF}_{\mathrm{t}}, \mathrm{UF}_{\mathrm{dd}}$ and their probability distributions are discussed in the respective section of this manuscript. Tests were performed, which show the validity of our approach. However, we are aware that adaptations of the UFs used in this study could be made with new insights for appropriate UFs suggestions.

Building the probabilistic species sensitivity distributions

The PSSDs were built in three steps. First, ecotoxicological values were converted into chronic NOECs. Second, all NOECs of one species were combined together in a probability distribution. Finally, PSSDs were extracted. The calculations were This article is protected by copyright. All rights reserved. 
performed with a script programmed in R (R Core Team, 2013), which requires six items as inputs:

- A table of ecotoxicity values (data points, DPs) extracted from the literature

- A table of UFs associated with these values to correct for the exposure duration $\left(U F_{t}\right)$

- A table of UFs associated with the ecotoxicity values to convert them to $\operatorname{NOECs}\left(U F_{d d}\right)$

- A coefficient of variation that is unique to all data points, representing the inter-laboratory variability $\left(C V_{D P}=30 \%\right.$,(Gottschalk and Nowack, 2013))

- A coefficient of variation that is unique to all uncertainty factors, representing the uncertainty associated with the use of non-substance-specific uncertainty factors $\left(C V_{U F}=50 \%\right)$

- A number of simulations

The following subsections describe the steps of the method used to obtain the PSSDs.

\section{Conversion of ecotoxicological data to NOECs}

The first step of the approach was to convert all ecotoxicity measurements (or data points, DP) extracted from the literature to chronic NOECs, based on the $U F_{t}$ and $U F_{d d}$ (Eq. 1):

$N O E C=\frac{D P}{U F_{t} \times U F_{d d}}$

Definition of species-specific probability distributions in generic cases (e.g. CNTs)

Second, a probability distribution was defined to represent the toxicity of the substance towards each species considered. The overall widths of these speciesspecific distributions were defined based on the range of NOECs obtained, and on the CVs defined above. The minimum and maximum of a species-specific distribution were determined by the uncertainties attributed to the lowest and largest calculated NOECs. These uncertainties were derived using error propagation, as in equation 2:

$\sigma_{N O E C}=\sqrt{\sigma_{D P}^{2}+\sigma_{U F_{t}}^{2}+\sigma_{U F_{d d}}^{2}}$

where $\sigma_{N O E C}$ is the relative uncertainty attributed to the lowest or largest $N O E C$, and $\sigma_{D P}, \sigma_{U F_{t}}$ and $\sigma_{U F_{d d}}$ are the relative uncertainties associated to the inter-laboratory variation of measurement, the UF used for the correction of chronic values $U F_{t}$ and the UF used for the dose-descriptors $U F_{d d}$. Since our coefficients of variation

This article is protected by copyright. All rights reserved. 
represent the maximum spread of triangular distributions, we used a factor of 2.45 to convert them into standard deviations and use error propagation (Eq. 4, based on (Kawecki et al., 2018)).

$C V_{N O E C, C N T}=\sqrt{\left(\frac{C V_{D P}}{2.45}\right)^{2}+\left(\frac{C V_{U F t}}{2.45}\right)^{2}+\left(\frac{C V_{U F} d d}{2.45}\right)^{2}} \cdot 2.45$

Three different cases occurred when building species-specific NOEC distributions: (1) One data point was available for one species, (2) Two data points were available for one species and (3) Three or more data points were available for one species. Each case was treated separately, as follows.

Case 1: One data point available for one species (Figure 1A). When only one data point was available for a species, a triangular distribution was built around the NOEC calculated as in Eq. 1. The mode of the distribution was defined as the NOEC, while the minimum and maximum of the distributions were calculated as in Eq. 4 and 5, respectively:

$\min =N O E C \cdot\left(1-C V_{N O E C, C N T}\right)(4)$

$\max =N O E C \cdot\left(1+C V_{N O E C, C N T}\right)(5)$

Case 2: Two data points available for one species (Figure 1B). When two data points were available for one species, a trapezoidal distribution was built. Both modal values of the distribution were calculated as in Eq. 1. The calculations of the minimum and maximum values of the distribution were calculated based on Eq. 6 and 7, respectively:

$\min =N O E C_{1} \cdot\left(1-C V_{N O E C, C N T_{1}}\right)(6)$

$\max =N O E C_{2} \cdot\left(1+C V_{N O E C, C N T_{2}}\right)(7)$

Case 3: Three or more data points available for one species (Figure 1C). In this case, a more complex distribution was defined, following several steps. By default, an equal probability was assumed to all NOEC values. Uniform distributions were therefore built between each NOEC, as in (Gottschalk and Nowack, 2013), resulting in what we will call a base step distribution. Because this approach produced unrealistic distributions in the case where two NOECs were equal, it was defined that for each instance where two NOECs were equal, the probability for this NOEC was doubled. In all cases, we chose to double the highest probability value that could be attributed with the NOEC ( $\mathrm{p}_{\mathrm{i} 1}$ in the example in Figure 1C). Similarly, when $n$ NOECs were equal, a weight of $n$ was attributed to this point in the probability distribution. Since in

This article is protected by copyright. All rights reserved. 
the base step distribution, two different probabilities can be attributed to each NOEC value, one from the left and one from the right, only the largest of the two probabilities was considered (top panel in Figure 1C). Once the individual weights were set for each NOEC, the probability between two subsequent NOECs was defined as a linear function. This procedure then yielded one probability distribution for each species. Finally, to represent the uncertainties associated with inter-laboratory variability and the non-substance-specific evaluation of UFs, the same approach was used as in Case 1 and Case 2: Triangular distributions were added at the extrema of the step probability distribution (bottom panel in Figure 1C, Eq. 8 and 9, NOEC being the highest NOEC obtained for the species):

$\min =N O E C_{1} \cdot\left(1-C V_{N O E C, C N T_{1}}\right)(8)$

$\max =N O E C_{n} \cdot\left(1+C V_{N O E C, C N T_{n}}\right)(9)$

Definition of species-specific probability distributions for a specific case: nano-Ag

For nano-Ag, probability distributions were defined based on coefficients of variation for inter-laboratory variations and $\mathrm{UF}_{\mathrm{dd}}$, and on minimum and maximum values for $\mathrm{UF}_{\mathrm{t}}$. Therefore, a slightly different approach was used than for the CNT-case. The CV used to find the minimum or the maximum values of a species-specific probability distribution included only the variations due to inter-laboratory variation and $\mathrm{UF}_{\mathrm{dd}}$ (Eq.10). The minimum obtained in this was then divided by 100, which is the maximum value of the probability distribution associated with $U_{\mathrm{t}}$ (Eq. 11). To find the maximum of the species-specific probability distribution, the "interim" maximum found with the $\mathrm{CV}$ was divided by the lowest value of the probability distribution associated with $\mathrm{UF}_{\mathrm{t}}$ (equal to 1), so remained as such (Eq. 12).

$$
\begin{aligned}
& C V_{N O E C, A g}=\sqrt{\left(\frac{C V_{D P}}{2.45}\right)^{2}+\left(\frac{C V_{U F} d d}{2.45}\right)^{2}} \cdot 2.45(10) \\
& \min =N O E C_{1} \cdot\left(1-C V_{N O E C, A g_{1}}\right) / 100(11) \\
& \max =N_{N O E C_{2}} \cdot\left(1+C V_{N O E C, A g_{2}}\right)(12)
\end{aligned}
$$

The minima and maxima obtained were then used in the same way as for CNTs to build the species-specific distributions.

\section{Derivation of the probabilistic species sensitivity distributions}

The PSSD graph represents the species sensitivity (or fraction of species affected) as a function of the NOEC. The ranges of species-specific NOEC distributions determined 
the range of concentrations in which the PSSDs were built. In each simulation, i.e. for each PSSD, one value was sampled from each species-specific distribution. All the extracted NOEC values were combined in a cumulative distribution to give a PSSD. This process was repeated 10’000 times to obtain 10’000 PSSDs. The probability associated with each ecotoxicological value in the species-specific distributions represented the likelihood that it was sampled in one simulation. In this way, all species available in the dataset were represented with equal weight, and the structure of the community represented was that of the dataset available.

Typical freshwater communities generally consist of approximately 65\% primary producers, $25 \%$ herbivores and $10 \%$ of carnivores (Forbes and Calow, 2002). The authors considered all invertebrates as herbivores and all fishes as carnivores. Since PSSDs should be representative of a general freshwater community, this typical structure was used to build generic PSSDs, although we acknowledge that this structure represents a very broadly simplified ecosystem. To this aim, the species available in the dataset were sampled randomly in each of the $10^{\prime} 000$ simulations so that the structure of the community represented was typical of freshwaters. In each simulation, $65 \%$ of the NOEC species-specific distributions from which values were sampled were of primary producers, $25 \%$ of invertebrates and $10 \%$ of fishes. All species available for the most underestimated trophic level were always considered in the calculations of the PSSDs. This number was set to the corresponding typical representation of the trophic level, and the numbers of values sampled for the other two trophic levels were determined based on the number of values in the most underestimated trophic level and the typical proportions of the other levels. Even though the number of values sampled in each trophic level stayed the same for all simulations, the species corresponding to each of the originally overestimated trophic levels were chosen randomly so that they would all be represented in the graph.

\section{Calculation of the predicted no effect concentration}

As recommended by REACH guideline R.10 (ECHA, 2008), the PNEC was determined by extracting the fifth percentile of the hazardous concentration for each PSSD calculated. These 10'000 values represent the probability distribution of the PNEC. The REACH guideline also requires the use of an UF ranging from 1 to 5 depending on the quality of the dataset used. Since the purpose of this article was to develop further the probabilistic elements in the method, we applied here an UF of 1 , although we are aware that future studies will need to define this factor to the best of their knowledge.

This article is protected by copyright. All rights reserved. 
Test of robustness and sensitivity of the method

The robustness of the PSSD $^{+}$approach was assessed by comparing the PNECs calculated to already published datasets for CNT and nano-Ag. Its sensitivity to the used dataset was tested by removing one data point (NOEC) from the dataset at a time. The percentage of change from one PNEC to another was calculated to interpret the results.

\section{Results and discussion}

\section{Further development of the PSSD approach}

Table 4 describes the differences of the $\operatorname{PSSD}^{+}$approach with that developed by Gottschalk and Nowack (2013) for each step towards the determination of a PNEC probability distribution. One of the main changes concerns the uncertainties considered to build probability distributions of individual NOECs. While the approach of Gottschalk and Nowack (2013) converts data points into NOEC values based on single values of UFs, our approach considers the uncertainties associated with the UFs. The other main change regards the number of PSSDs derived and the calculation of the PNEC distribution. Instead of applying a confidence interval to a single PNEC value, the probability distribution derived here is directly based on the multiple individual HC5s obtained from the PSSD data.

The PSSD ${ }^{+}$approach has several advantages compared to conventional SSD methods, which relates to the handling of the data and uncertainties associated. Compared to conventional SSDs that are usually based on one data point per species (e.g. geometric mean or lowest value), the PSSD ${ }^{+}$approach considers all values reported equally and thereby avoids a bias from data selection (Fox, 2015). Hence, this PSSD approach stays closer to the original data and avoids losing information by aggregating the data. It is therefore able to cope better with large datasets. Conventional SSDs also assume a predefined model that does not always accurately represent the ecotoxicity to all species, since it will be representative of a general trend only, and not of the individual responses of species. Here, since all data are considered in the final PSSD curves, no bias is entailed by curve fitting. The PSSD $^{+}$approach is therefore also preferable for small datasets. In the end, this method takes into account all elements of inter-test variation (Hickey and Craig, 2012): Inter-laboratory variations is taken into account explicitly with a coefficient of variation of $30 \%$; intra-species variations are considered by the fact that we stay as close as possible to the raw data points, which are numerous for many species; experimental variations and those raised by the use of different models to derive the ecotoxicological values are taken into account implicitly

This article is protected by copyright. All rights reserved. 
by not excluding any study based on such criteria: if they exist in the literature, all experimental conditions and modelling strategies are included in our work.

\section{Case studies}

The PSSDs of CNTs in freshwater were built on 39 ecotoxicity values reported in the literature and cover 10 species, while 158 values covering 21 species were available to build the PSSDs of nano-Ag (Figure 2). Both datasets provide a good representation of the trophic chain, from eukaryotes to fishes, but the dataset on nano-Ag is more complete since it includes plants, an insect and a snail, types of organisms for which the ecotoxicity of CNTs were not tested.

The PSSDs of both nano-Ag and CNTs shown in Figure 2 were built on the whole datasets. They represent the sensitivity of a community, which would have the structure of the dataset (Tables 5 and S4). The shaded areas represent various quantiles of the PSSDs, while the green points represent the NOECs that were calculated from the data available in the literature. These points are grouped per species and are reported on the graph only as a reference. The order in which the species appear on the y-axis is only defined by the geometric mean of their NOECs: the species with the lowest geometric mean of NOECs is considered as the most sensitive and therefore appears at the bottom of the graph. This is different from the order in which the species might appear on a PSSD, where they are ranked based on the NOEC values that were sampled in the calculation. The order of species is therefore not necessarily the same on each PSSD. This explains why, for example, the highest NOEC value found for $D$. rerio is considered on the highest levels of the PSSD, and not on the level on which all NOECs of $D$. rerio are reported.

Daphnia magna was shown to be the species most sensitive to CNTs; the lowest NOEC found for this organism was $13 \mu \mathrm{g} . \mathrm{L}^{-1}$ by Zhu et al. (2009). The amphibian Ambystoma mexicanum presented a NOEC of $10^{5} \mu \mathrm{g} . \mathrm{L}^{-1}$ (Mouchet et al., 2007) and was the least sensitive species. The PNEC empirical probability distribution obtained from the PSSD had a mean of $86 \mu \mathrm{g} . \mathrm{L}^{-1}$ with $25^{\text {th }}$ and $75^{\text {th }}$ quantiles of 32 and 111 $\mu \mathrm{g} . \mathrm{L}^{-1}$, respectively (Table 6).

Organisms were generally shown to be more sensitive to nano-Ag than to CNTs. Based on the geometric means of the NOECs, the species most sensitive to nano-Ag was found to be Gammarus fossarum, for which one NOEC was available (10 ng.L ${ }^{-1}$, (Arce Funck et al., 2013)). However, the lowest NOEC of all was 1.5 ng.L $\mathrm{L}^{-1}$, which was obtained when exposing Ceriodaphnia dubia to nano-Ag (Angel et al., 2013). Paramecium caudatum was the least sensitive species, with a NOEC of $0.25 \mathrm{ng} . \mathrm{L}^{-1}$ (Kvitek et al., 2009). The range of the histogram of the simulated PNECs of nano-Ag

This article is protected by copyright. All rights reserved. 
was 3 to 4 orders of magnitude lower than that of CNTs, with a mean of 77 ng. $\mathrm{L}^{-1}$ and $25^{\text {th }}$ and $75^{\text {th }}$ quantiles of 11 and 126 ng. L $^{-1}$, respectively.

As with any model, the results rely heavily on the input data, here the NOECs, and in the way they are handled. These results are therefore only valid for the species included in this assessment, and not, as would be most often assumed, on all communities of species living in freshwater environments (Forbes and Calow, 2002). Fox (2015) underlines the fact that it is crucial to select species from all taxonomic groups relevant to the compartment under study. According to the REACH guidelines, all important taxonomic groups living in pelagic freshwater seem to be included in the data set for nano-Ag, while the occurrences of a higher plant, an insect and a family in a phylum other than Arthropoda or Chordata are missing for CNTs (Table 1). Regarding other guidelines, such as those of the US EPA (Stephen et al., 1985) and of the Canadian Council of Ministers of the Environment (CCME, 2007), criteria are still met for nano-Ag but not for CNTs (Table S3). Results could therefore certainly change with regard to CNTs if more data, especially on the types of organisms lacking, were included in the assessment. It has to be noted that future SSD as well as PSSD $^{+}$assessments should differentiate datasets according to the ecotoxicological endpoints tested, because the consideration of different endpoints such as mortality and growth inhibition introduces larger uncertainties to the results. Despite this fact seems to be acknowledged by researchers, some regulations allow such data aggregation as pointed out by Hickey and Craig (2012).

Testing the sensitivity of the PNEC results to data point variations

The sensitivity test of the PSSD $^{+}$approach was performed on the initial datasets, without any rearrangement of the structures of the biomes (Figure 3). Each graph shows the difference in the mean PNEC obtained when removing one specific NOEC from the overall distribution, these NOEC values being ordered ascendingly on the horizontal axis. It can be seen that both in the case of a lower number of ecotoxicity values available (CNTs) and that of a larger data set (nano-Ag), the maximum change in the calculated mean PNEC stays in all cases except one within a factor of $50 \%$ when any NOEC value is removed. This shows that, unlike fitting approaches, the PSSD $^{+}$can handle both small and large datasets.

The highest change of the mean PNEC for CNTs was observed when the lowest NOEC was removed from the PSSD ( $+40 \%)$. Removal of the $3^{\mathrm{d}}, 5^{\text {th }}, 8^{\text {th }}$ and $14^{\text {th }}$ NOECs also resulted in considerable changes of the PNEC, of about $20 \%$ or higher. All these NOECs were associated with the two most sensitive species, D. magna and C. dubia, which explains why they have the highest influence on the calculation of the $5^{\text {th }}$ percentiles of the PSSDs. It is worth highlighting that both these species are

This article is protected by copyright. All rights reserved. 
crustaceans, and that no other crustacean was found at lower toxicities. This might indicate that this type of organism is more sensitive than others to CNTs, although one should keep in mind the limited number of species for which data was available and therefore the potentially limited representation of the overall sensitivity of species towards CNTs.

Removing the lowest NOECs of nano-Ag induced a significant change in the resulting mean PNEC, but the highest change was observed only for the $6^{\text {th }}$ NOEC of nano-Ag (+201\%) corresponding to the removal of the NOEC of $G$. fossarum. The fact that only one data point was available for this species explains why its removal lead to such a high difference in the PNEC calculated, since C. dubia $\left(2^{\text {nd }}\right.$ ranked in the complete nano-Ag dataset) becomes the most sensitive species and the lowest part of the PSSD is shifted to higher values (i.e. less toxic). Therefore, it appears that it is not only the values of the NOECs considered that influence the value of the PNEC, but also the overall sensitivity of the species to which these NOECs are associated. Other significant changes of the mean PNEC, higher than 30\%, are due to the removal of points associated with $C$. dubia, the second most sensitive species.

A common criticism to SSDs is the basic assumption of exchangeability of the species selected allowing their "random sampling". Craig et al. (2012) have shown that for some species, such as Oncorhynchus mykiss or Carassius auratus, this assumption is improper affecting the $\mathrm{HC}_{5}$ derivation significantly, which is also visible in Figure 3. Some methods were provided to tackle this challenge (Craig et al., 2012, Belanger et al., 2017) and should be considered by environmental risk practitioners using the SSD and PSSD ${ }^{+}$methods.

\section{Generic assessment of a typical community structure}

To better represent the sensitivity of a typical freshwater community to the chosen nanomaterials and not that of the community built by the availability of studies on specific species, PSSDs were built on the weighted datasets. Tables 5 and S4 show that, in the dataset for CNTs, the proportions of primary producers and herbivores were underestimated by about $15 \%$ and $5 \%$, respectively, and that of carnivores was overestimated by $20 \%$. The proportions of primary producers considered for nano-Ag was underestimated by about $25 \%$ and those of herbivores and carnivores were overestimated by about 15\%. The PNEC of CNT obtained with a typical structure did not differ from the PNEC obtained with all species from which data could be obtained. For nano-Ag, the mean PNEC was smaller by a factor of 1.4 when a typical structure of ecological community was used in the calculations (Table 5).

This article is protected by copyright. All rights reserved. 
The conversion of ecotoxicity values reported in the literature to chronic NOECs gives rise to uncertainties, associated with both $\mathrm{UF}_{\mathrm{dd}}$ and $\mathrm{UF}_{\mathrm{t}}$. The use of uncertainty factors is recommended in regulation and test guidelines. However, these are neither species-specific nor substance-specific. Brix et al. (2001) showed that they are different among species for a same substance, while Chen et al. (2018) showed that they could be different for different nanomaterials. These authors evaluated the ratios of $\mathrm{HC}_{5}$ derived from different dose descriptors (i.e. $\mathrm{UF}_{\mathrm{dd}}$ ) divided by the $\mathrm{HC}_{5}$ derived from NOEC values for nano-Ag. They found $\mathrm{HC}_{5}-\mathrm{LC}_{50} / \mathrm{HC}_{5}-\mathrm{NOEC}, \mathrm{HC}_{5}-\mathrm{EC}_{50} / \mathrm{HC}_{5}-$ NOEC and LOEC/NOEC equal to 10, 15.8 and 0.5. However, their calculations were based on five data points for LOECs and NOECs: even though they are a good indication, they cannot be considered as definitive. This might also explain why the $\mathrm{HC}_{5}$ based on NOECs seems higher than that based on LOECs. Nevertheless, the ratios obtained by Chen et al. (2018) for $\mathrm{LC}_{50} \mathrm{~S}$ and $\mathrm{EC}_{50} \mathrm{~S}$ are in the range of uncertainty that were considered in the PSSD ${ }^{+}$method. An uncertainty of $\pm 50 \%$ around these uncertainty factors therefore seems reasonable.

The modal value of 10 used for the conversion of acute to chronic values (i.e. $\mathrm{UF}_{\mathrm{t}}$ ) could also be discussed. To this end, we took inspiration from Duboudin et al. (2004) and separated the calculations of PSSDs and PNECs probability distributions from chronic and acute datasets (Table 6). The resulting PNECs were compared, to see if the difference of their means would be around a factor of 10 . Only the species for which both chronic and acute data were available were considered in these calculations. For CNTs, only D. magna could be included, so we compared the mean of the chronic NOECs available for this species to the mean of the acute NOEC. The chronic mean was lower than the acute mean, by a factor of 12.4. This factor was located at the higher end of the range of uncertainty attributed to the uncertainty factor (5 to 15). The use of such a range seems therefore rather conservative, as also illustrated by the fact that the PNEC calculated with the whole dataset was lower than the PNEC calculated with the chronic dataset only. However, the numbers of species included in the acute and chronic assessments of PNECs were low, so it is reasonable to keep an uncertainty range around the conversion factor. For nano-Ag, three species could be considered in the calculations so PNECs could be calculated. The chronic PNEC was lower than the acute PNEC, by a factor of 1.8. Again, this value is within the range of the probability distribution associated with $U_{\mathrm{t}}$, ranging from 1 to 100 with a modal value of 10 . The PNEC of nano-Ag calculated with the whole dataset was lower than both the chronic and acute PNECs, which showed again that our method is rather conservative.

This article is protected by copyright. All rights reserved. 


\section{Conclusions}

Ecotoxicological hazard assessments have to determine the PNEC value for a given substance to be used in a regulatory context. Unlike deterministic approaches that focus on single species of a compartment, SSD and PSSD methods are recommended to calculate a PNEC that is representative for the whole biological community because they allow the consideration of several species at the same time. In order to comply with regulations, chronic data on ecotoxicological effects are preferred in a regulatory context, although this preference may differ depending on the study and management objective. However, since the chronic data availability is more limited than that of acute data, UFs for acute-to-chronic conversion and also dose-descriptors are one potential mean to make chronic and acute data comparable. The adequacy of such data conversion is controversially discussed, as these UFs are particularly dependent on the species and substance considered. Also, the species relevance was discussed to have a critical impact on the PNEC values, when a weighting scheme is applied to consider key species in an environmental compartment.

In this light, we advanced the PSSD approach on three aspects to develop the PSSD tool. First, we incorporated additional probabilistic elements to this computational method in order to consider the uncertainty associated to UFs by using probability distributions instead of single values. By doing so, we cannot answer the question of the truly correct UF that should be used, but our approach can consider the uncertainty related to UFs for deriving the PNEC. Second, the new PSSD method computes 10'000 PSSDs based on a Monte-Carlo routine. For each PSSD calculated, the $\mathrm{HC}_{5}$ was extracted to provide a PNEC distribution based on all data available and their associated uncertainty. Third, the novel PSSD approach is capable to consider a species weighting according to a typically constituted biome.

We tested the PSSD ${ }^{+}$approach regarding the robustness and sensitivity based on published datasets on CNT and nano-Ag, representing two cases of small and bigger datasets. The evaluation of the UFs distributions and species weighting showed that the proposed PSSD method is plausible and indicated quasi-stability of the results when species weighting was applied. Furthermore, we demonstrated that the PSSD $^{+}$approach can handle both limited and larger datasets by avoiding the fitting problem of conventional SSDs as the resulting PNECs are a closer representation of the data available. The sensitivity testing towards data set variations showed that in all but one case, the results changed by a factor of less than 2 . Therefore, the $\mathrm{PSSD}^{+}$approach is relatively insensitive against missing data points as long as the most sensitive species is included. This underlines the need for adequate data rather than more data, which is why the application of the PSSD ${ }^{+}$approach requires a sound preselection of studies by

This article is protected by copyright. All rights reserved. 
experts. Nevertheless, future developments of the $\mathrm{PSSD}^{+}$can address this issue by incorporating data quality aspects. Finally, the PSSD ${ }^{+}$approach can be not only applied to ENMs (Wigger and Nowack, 2019) but also to any other substance such as microplastics (Adam et al., 2019) or chemicals.

\section{Acknowledgements}

H.W. and V.A. were supported by caLIBRAte which has received funding from the European Union's Horizon 2020 Research and Innovation Programme under Grant Agreement 686239.

\section{Disclaimer}

The authors declare no conflict of interests.

\section{Data Availability Statement}

The simulation framework is available as a software package at https://doi.org/10.5281/zenodo.3267194

\section{References}

ADAM, V., YANG, T. \& NOWACK, B. 2019. Towards an Ecotoxicological Risk Assessment of Microplastics: Comparison of Available Hazard and Exposure Data in Freshwaters. Environ Toxicol Chem, 38, 436-447.

ALDENBERG, T. \& SLOB, W. 1993. Confidence limits for hazardous concentrations based on logistically distributed NOEC toxicity data. Ecotoxicol Environ Saf, 25, 48-63.

ANGEL, B. M., BATLEY, G. E., JAROLIMEK, C. V. \& ROGERS, N. J. 2013. The impact of size on the fate and toxicity of nanoparticulate silver in aquatic systems. Chemosphere, 93, 359-65.

ARCE FUNCK, J., DANGER, M., GISMONDI, E., COSSU-LEGUILLE, C., GUEROLD, F. \& FELTEN, V. 2013. Behavioural and physiological responses of Gammarus fossarum (Crustacea Amphipoda) exposed to silver. Aquat Toxicol, 142-143, 73-84.

AZIMONTI, G., GALIMBERTI, F., MARCHETTO, F., MENABALLI, L., ULlUCCI, S., PELLICIOLI, F., CAFFI, A., CERIANI, L., IPPOLITO, A., MORETTO, A., DE BOER, W. \& VAN DER VOET, H. 2015. Comparison of NOEC values to EC10/EC20 values, including confidence intervals, in aquatic and terrestrial ecotoxicological risk assessment. In: EFSA SUPPORTING PUBLICATION 2015:EN-906 (ed.).

This article is protected by copyright. All rights reserved. 
BEASLEY, A., BELANGER, S. E., BRILL, J. L. \& OTTER, R. R. 2015. Evaluation and comparison of the relationship between NOEC and EC10 or EC20 values in chronic Daphnia toxicity testing. Environ Toxicol Chem, 34, 2378-84.

BELANGER, S., BARRON, M., CRAIG, P., DYER, S., GALAY-BURGOS, M., HAMER, M., MARSHALL, S., POSTHUMA, L., RAIMONDO, S. \& WHITEHOUSE, P. 2017. Future needs and recommendations in the development of species sensitivity distributions: Estimating toxicity thresholds for aquatic ecological communities and assessing impacts of chemical exposures. Integr Environ Assess Manag, 13, 664-674.

BRIX, K. V., DEFOREST, D. K. \& ADAMS, W. J. 2001. Assessing acute and chronic copper risks to freshwater aquatic life using species sensitivity distributions for different taxonomic groups. Environ Toxicol Chem, 20, 18461856.

CCME 2007. A Protocol for the Derivation of Water Quality Guidelines for the Protection of Aquatic Life. Part II: Guideline derivation. Canadian Council of Ministers of the Environment.

CHEN, G., PEIJNEnBURG, W. J. G. M., XIAO, Y. \& VIJVER, M. G. 2018. Developing species sensitivity distributions for metallic nanomaterials considering the characteristics of nanomaterials, experimental conditions, and different types of endpoints. Food Chem Toxicol, 112, 563-570.

COLL, C., NOTTER, D., GOTTSCHALK, F., SUN, T., SOM, C. \& NOWACK, B. 2016. Probabilistic environmental risk assessment of five nanomaterials (nanoTiO2, nano-Ag, nano-ZnO, CNT, and fullerenes). Nanotoxicology, 10, 436-44.

CRAIG, P., HICKEY, G. L., LUTTIK, R. \& HART, A. 2012. Species nonexchangeability in probabilistic ecotoxicological risk assessment. J. R. Statist. Soc. A, 175, 243-262.

DOWSE, R., TANG, D., PALMER, C. G. \& KEFFORD, B. J. 2013. Risk assessment using the species sensitivity distribution method: data quality versus data quantity. Environ Toxicol Chem, 32, 1360-9.

ECHA 2008. Guidance on information requirements and chemical safety assessment Chapter R.10 : Characterisation of dose [concentration]-response for environment. Helsinki, Finland: European Chemicals Agency (ECHA).

FORBES, V. E. \& CALOW, P. 2002. Species Sensitivity Distributions Revisited: A Critical Appraisal. Hum Ecol Risk Assess, 8, 473-492.

FOX, D. R. 2015. Selection bias correction for species sensitivity distribution modeling and hazardous concentration estimation. Environ Toxicol Chem, 34, 2555-63.

FOX, D. R. \& LANDIS, W. G. 2016. Don't be fooled-A no-observed-effect concentration is no substitute for a poor concentration-response experiment. Environ Toxicol Chem, 35, 2141-8.

This article is protected by copyright. All rights reserved. 
GIESE, B., KLAESSIG, F., PARK, B., KAEGI, R., STEINFELDT, M., WIGGER, H., GLEICH, A. V. \& GOTTSCHALK, F. 2018. Risks, Release and Concentrations of Engineered Nanomaterial in the Environment. Nature Scientific Reports, 8:1565.

GOTTSCHALK, F. \& NOWACK, B. 2013. A probabilistic method for species sensitivity distributions taking into account the inherent uncertainty and variability of effects to estimate environmental risk. Integr Environ Assess Manag, 9, 79-86.

GREEN, J. W., SPRINGER, T. A. \& STAVELEY, J. P. 2013. The drive to ban the NOEC/LOEC in favor of ECX is misguided and misinformed. Integr Environ Assess Manag, 9, 12-6.

HARMON, A. R., KENNEDY, A. J., LAIRD, J. G., BEDNAR, A. J. \& STEEVENS, J. A. 2017. Comparison of acute to chronic ratios between silver and gold nanoparticles, using Ceriodaphnia dubia. Nanotoxicology, 11, 1127-1139.

HICKEY, G. L. \& CRAIG, P. S. 2012. Competing statistical methods for the fitting of normal species sensitivity distributions: recommendations for practitioners. Risk Anal, 32, 1232-43.

ISNARD, P., FLAMMARION, P., ROMAN, G., BABUT, M., BASTIEN, P., BINTEIN, S., ESSERMEANT, L., FERARD, J. F., GALLOTTI-SCHMITT, S., SAOUTER, E., SAROLI, M., THIEBAUD, H., TOMASSONE, R. \& VINDIMIAN, E. 2001. Statistical analysis of regulatory ecotoxicity tests. Chemosphere, 45, 659-69.

IWASAKI, Y., KOTANI, K., KASHIWADA, S. \& MASUNAGA, S. 2015. Does the Choice of NOEC or EC10 Affect the Hazardous Concentration for 5\% of the Species? Environ Sci Technol, 49, 9326-30.

JAGER, T. 2012. Bad habits die hard: the NOEC's persistence reflects poorly on ecotoxicology. Environ Toxicol Chem, 31, 228-9.

KAWECKI, D., SCHEEDER, P. \& NOWACK, B. 2018. Probabilistic Material Flow Analysis of Seven Commodity Plastics in Europe. Environ Sci Technol, 52, 9874-9888.

KIM, E., KIM, S.-H., KIM, H.-C., LEE, S. G., LEE, S. J. \& JEONG, S. W. 2011. Growth inhibition of aquatic plant caused by silver and titanium oxide nanoparticles. J Toxicol Environ Health Sci, 3, 1-6.

KVITEK, L., VANICKOVA, M., PANACEK, A., SOUKUPOVA, J., DITTRICH, M., VALENTOVA, E., PRUCEK, R., BANCIROVA, M., MILDE, D. \& ZBORIL, R. 2009. Initial Study on the Toxicity of Silver Nanoparticles (NPs) against Paramecium caudatum. J Phys Chem C, 113, 4296-4300.

LASKOWSKI, R. 1995. Some Good Reasons to Ban the Use of Noec, Loec and Related Concepts in Ecotoxicology. Oikos, 73, 140-144.

This article is protected by copyright. All rights reserved. 
MONTI, G. S., FILZMOSER, P. \& DEUTSCH, R. C. 2018. A Robust Approach to Risk Assessment Based on Species Sensitivity Distributions. Risk Anal, 38, 2073-2086.

MOUCHET, F., LANDOIS, P., FLAHAUT, E., PINELLI, E. \& GAUTHIER, L. 2007. Assessment of the potentialin vivoecotoxicity of Double-Walled Carbon Nanotubes (DWNTs) in water, using the amphibianAmbystoma mexicanum. Nanotoxicology, 1, 149-156.

NEWMAN, M. C., OWNBY, D. R., MEZIN, L. C. A., POWELL, D. C., CHRISTENSEN, T. R. L., LERBERG, S. B. \& ANDERSON, B. A. 2000. Applying species-sensitivity distributions in ecological risk assessment: Assumptions of distribution type and sufficient numbers of species. Environ Toxicol Chem, 19, 508-515.

OECD 2000. OECD Guideline for the testing of chemicals - Fish, Juvenile Growth Test.

OECD 2004. OECD Guideline for testing of chemicals - Daphnia sp., Acute Immobilisation Test.

OECD 2006a. OECD Guidelines for the testing of chemicals - Freshwater Alga and Cyanobacteria, Growth Inhibition Test.

OECD 2006b. Test No. 227: Terrestrial Plant Test: Vegetative Vigour Test. OECD Guidelines for the Testing of Chemicals, Section 2. Paris: OECD Publishing.

OECD 2009. OECD Guideline for the testing of chemicals - 21-day Fish Assay: A Short-Term Screening for Oestrogenic and Androgenic Activity, and Aromatase Inhibition.

OECD 2012. OECD Guideline for the testing of chemicals - Daphnia magna Reproduction Test.

OECD 2016a. OECD Guideline for the testing of chemicals - Lymnaea stagnalis Reproduction Test.

OECD 2016b. OECD Guideline for the testing of chemicals - Potamopyrgus antipodarum Reproduction Test.

POSTHUMA, L., SUTER, G. W. \& TRAAS, T. P. 2002. Species Sensitivity Distributions in Ecotoxicology, Boca, Raton, London, New York, Washington D.C, CRC Press Taylor \& Francis Group.

R CORE TEAM 2013. R: A language and environment for statistical computing. 3.2.3 ed. Vienna, Austria: R Foundation for Statistical Computing.

RAIMONDO, S., MONTAGUE, B. J. \& BARRON, M. G. 2007. Determinants of variability in acute to chronic toxicity ratios for aquatic invertebrates and fish. Environ Toxicol Chem, 26, 2019-2023.

This article is protected by copyright. All rights reserved. 
SCHWAB, F., BUCHELI, T. D., LUKHELE, L. P., MAGREZ, A., NOWACK, B., SIGG, L. \& KNAUER, K. 2011. Are carbon nanotube effects on green algae caused by shading and agglomeration? Environ Sci Technol, 45, 6136-44.

SEMENZIN, E., LANZELLOTTO, E., HRISTOZOV, D., CRITTO, A., ZABEO, A., GIUBILATO, E. \& MARCOMINI, A. 2015. Species sensitivity weighted distribution for ecological risk assessment of engineered nanomaterials: the nTiO2 case study. Environ Toxicol Chem, 34, 2644-59.

SMETANOVA, S., BLAHA, L., LIESS, M., SCHAFER, R. B. \& BEKETOV, M. A. 2014. Do predictions from Species Sensitivity Distributions match with field data? Environ Pollut, 189, 126-33.

STEPHEN, C. E., MOUNT, D. I., HANSEN, D. J., GENTILE, J. R., CHAPMAN, G. A. \& BRUNGS, W. A. 1985. Guidelines for Deriving Numerical National Water Quality Criteria for the Protection of Aquatic Organisms and Their Issues. US EPA.

WANG, Y., KALININA, A., SUN, T. \& NOWACK, B. 2016. Probabilistic modeling of the flows and environmental risks of nano-silica. Sci Total Environ, 545546, 67-76.

WANG, Y. \& NOWACK, B. 2018. Environmental risk assessment of engineered nano-SiO2 , nano iron oxides, nano-CeO2 , nano-Al2O3, and quantum dots. Environ Toxicol Chem, 37, 1387-1395.

WANG, Y., ZHANG, L., MENG, F., ZHOU, Y., JIN, X., GIESY, J. P. \& LIU, F. 2015. Improvement on species sensitivity distribution methods for deriving site-specific water quality criteria. Environ Sci Pollut Res Int, 22, 5271-82.

WIGGER, H. \& NOWACK, B. 2019. Material-specific properties applied to an environmental risk assessment of engineered nanomaterials - implications on grouping and read-across concepts. Nanotoxicology, in press.

XU, F.-L., LI, Y.-L., WANG, Y., HE, W., KONG, X.-Z., QIN, N., LIU, W.-X., WU, W.-J. \& JORGENSEN, S. E. 2015. Key issues for the development and application of the species sensitivity distribution (SSD) model for ecological risk assessment. Ecol Indic, 54, 227-237.

ZHU, X., ZHU, L., CHEN, Y. \& TIAN, S. 2009. Acute toxicities of six manufactured nanomaterial suspensions to Daphnia magna. J Nanopart Res, 11, 67-75.

This article is protected by copyright. All rights reserved. 


\section{Figures}

Figure 1: Approach used to define species-specific probability distributions of ecotoxicity in cases where (A) one data point was available, (B) two data points were available, (C) three or more data points were available, $N O E C_{i}$ appears twice in the dataset while all other NOECs appear once. The top panel of figure $C$ represents the species-specific probability distributions without consideration of inter-laboratory variability and uncertainty associated to uncertainty factors. These variability and uncertainty are added on the bottom panel of figure C. Conc.: Concentration. $\mathrm{p}_{\mathrm{i} 1}$ and $\mathrm{p}_{\mathrm{i} 2}$ : first and second probability values that could be associated with $N O E C_{i}$.

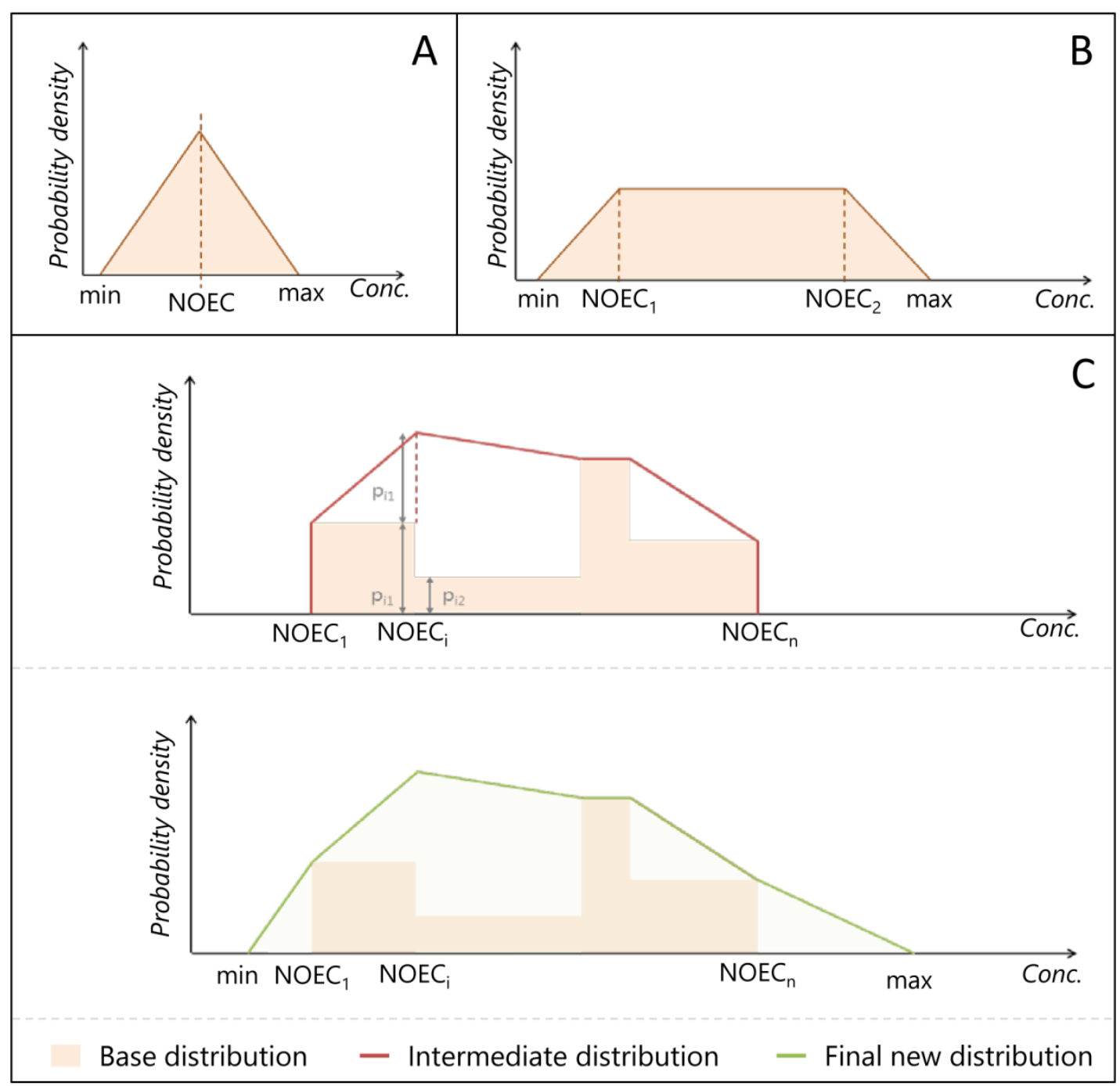

This article is protected by copyright. All rights reserved. 
Figure 2: Probabilistic species sensitivity distributions and histograms of the simulated predicted-no effect concentration of CNT (A) and nano-Ag (B) in freshwater

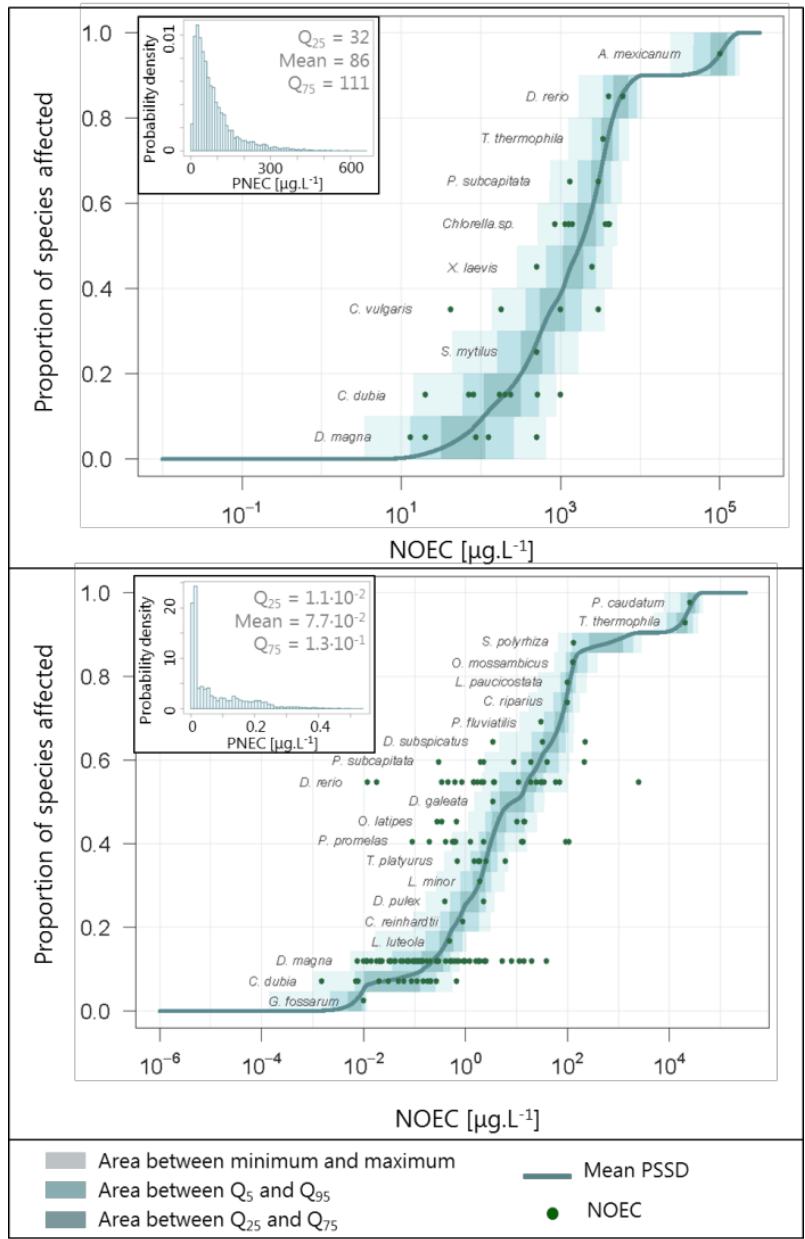

Figure 3: Differences in mean PNECs obtained when one NOEC value was removed from the probabilistic species sensitivity distribution. This calculation is based on the initial dataset that did not include any changes to biome structure.

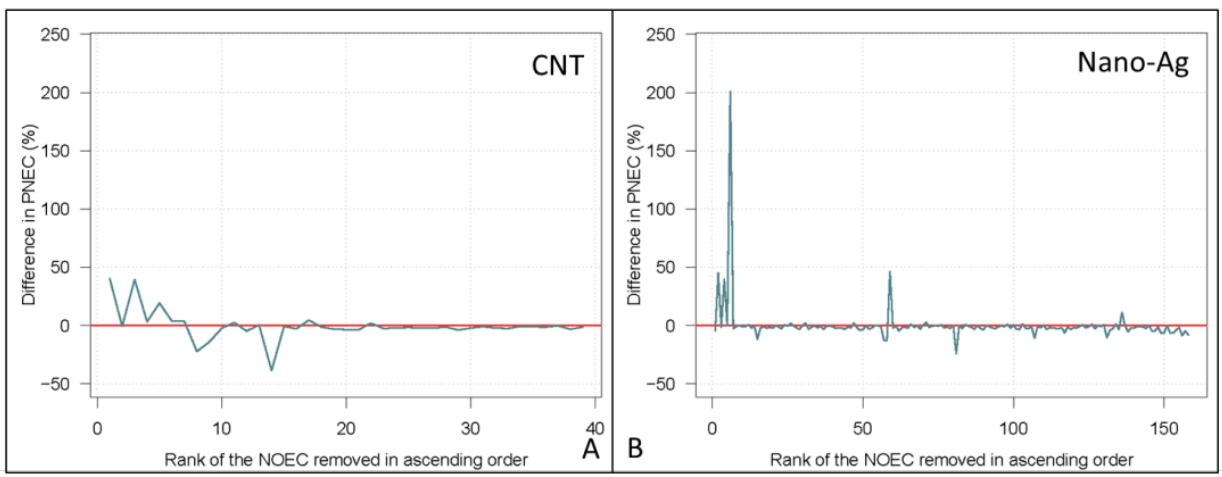

This article is protected by copyright. All rights reserved. 
Table 1: Characteristics of CNT and nano-Ag ecotoxicity datasets used to build the PSSDs. Criteria regarding occurrences of certain types of organisms are based on REACH guideline R.10 (ECHA, 2008)

\begin{tabular}{|l|c|c|}
\hline Characteristic of dataset & CNT & Nano-Ag \\
\hline Number of data points & 39 & 158 \\
\hline Number of species & 10 & 21 \\
\hline Proportion of chronic data points & $49 \%$ & $10 \%$ \\
\hline Occurrence of fish & Yes & Yes \\
\hline Occurrence of an algae & Yes & Yes \\
\hline Occurrence of a higher plant & No & Yes \\
\hline Occurrence of a crustacean & Yes & Yes \\
\hline Occurrence of an insect & No & Yes \\
\hline Occurrence of a second family in the phylum Chordata & Yes & Yes \\
\hline Occurrence of a family in a phylum other than Arthropoda or Chordata (e.g. Rotifera, & Yes \\
\hline Occurrence of a family in any order of insect or any phylum not already represented & No & Yes \\
\hline
\end{tabular}

This article is protected by copyright. All rights reserved. 
Table 2: Uncertainty factors used to convert acute to chronic values $\left(U F_{t}\right)$. An $U F_{t}$ of 10 was applied to values resulting from tests considered acute, while an $\mathrm{UF}_{\mathrm{t}}$ of 1 was applied to values resulting from chronic bioassays

\begin{tabular}{|c|c|c|c|}
\hline Type of organism & $\begin{array}{l}\text { Exposure time } \\
\text { (days) }\end{array}$ & $\begin{array}{c}\mathrm{UF}_{\mathrm{t}} \\
\text { modal } \\
\text { value }\end{array}$ & Reference \\
\hline Algae & $\begin{array}{l}<3 \\
\geq 3\end{array}$ & $\begin{array}{l}10 \\
1\end{array}$ & (OECD, 2006a) \\
\hline Plants $^{\mathrm{i}}$ & $\begin{array}{l}<28 \\
\geq 28\end{array}$ & $\begin{array}{l}10 \\
1\end{array}$ & (OECD, 2006b) \\
\hline Crustacea $^{\mathrm{ii}}$ & $\begin{array}{l}<21 \\
\geq 21\end{array}$ & $\begin{array}{l}10 \\
1\end{array}$ & (OECD, 2004, OECD, 2012) \\
\hline Mollusca & $\begin{array}{l}<28 \\
\geq 28\end{array}$ & $\begin{array}{l}10 \\
1\end{array}$ & $\begin{array}{c}\text { (OECD, 2016a, OECD, } \\
\text { 2016b) }\end{array}$ \\
\hline Fish & $\begin{array}{l}<28 \\
\geq 28\end{array}$ & $\begin{array}{l}10 \\
1\end{array}$ & (OECD, 2000, OECD, 2009) \\
\hline
\end{tabular}

Table 3: Uncertainty factors used to convert dose descriptors into NOECs $\left(\mathrm{UF}_{\mathrm{dd}}\right)$.

\begin{tabular}{|c|c|c|}
\hline $\begin{array}{c}\text { Type of dose- } \\
\text { descriptor }\end{array}$ & $\begin{array}{c}\text { UF }_{\text {dd }} \\
\text { modal value }\end{array}$ & Reference / comment \\
\hline $\begin{array}{c}\mathrm{LC}_{25-50} ; \mathrm{EC}_{25-50} ; \\
\mathrm{IC}_{25-50}\end{array}$ & 10 & Kim et al. (2011);Schwab et al. (2011) \\
\hline $\mathrm{LC}_{20} ; \mathrm{EC}_{20} ; \mathrm{IC}_{20}$ & 2 & Beasley et al. 2015; Azimonti et al. (2015) \\
\hline LOEC & 2 & (ECHA, 2008), Table R.10-1 \\
\hline $\mathrm{MIC}$ & 2 & Equal to LOEC \\
\hline $\mathrm{LC}_{10} ; \mathrm{EC}_{10} ; \mathrm{IC}_{10}$ & 1 & Beasley et al. (2015); Azimonti et al. (2015) \\
\hline
\end{tabular}

This article is protected by copyright. All rights reserved. 


\begin{tabular}{|c|c|c|}
\hline HONEC & 1 & Equal to NOEC \\
\hline
\end{tabular}

Table 4: Comparison of the PSSD $^{+}$with that of Gottschalk and Nowack (2013). Changes from one method to another are highlighted in bold.

\begin{tabular}{|c|c|c|}
\hline Step & $\begin{array}{l}\text { Gottschalk and Nowack } \\
(2013)\end{array}$ & PSSD $^{+}$ \\
\hline $\begin{array}{l}\text { 1. Convert } \\
\text { measurements to } \\
\text { NOECs }\end{array}$ & $\begin{array}{l}\text { NOECs are determined as } \\
\text { probability distributions, based } \\
\text { on the inter-laboratory variation } \\
\text { (coefficient of variation }=30 \% \text { ) } \\
\text { and single values of } \mathrm{UF}_{\mathrm{t}} \text { and } \\
\mathrm{UF}_{\mathrm{dd}} \text {. }\end{array}$ & $\begin{array}{l}\text { NOECs are determined as } \\
\text { probability distributions, based } \\
\text { on uncertainties associated with } \\
\text { the measurement (coefficient of } \\
\text { variation }=30 \% \text { ) and with } \mathbf{U F}_{\mathbf{t}} \\
\text { and } \mathbf{U F}_{\mathbf{d d}} \text { (coefficient of } \\
\text { variation }=\mathbf{5 0 \%} \text { when not } \\
\text { more accurate information is } \\
\text { available). }\end{array}$ \\
\hline $\begin{array}{l}\text { 2. Combine all } \\
\text { NOECs of one } \\
\text { species in one } \\
\text { probability } \\
\text { distribution }\end{array}$ & $\begin{array}{l}\text { In case of one measurement } \\
\text { available for a species, a } \\
\text { triangular distribution of the } \\
\text { NOEC is built. } \\
\text { In case of two measurements } \\
\text { available for one species, a } \\
\text { trapezoidal distribution is built. } \\
\text { In case of three or more } \\
\text { measurements available for one } \\
\text { species, a step distribution is } \\
\text { built. }\end{array}$ & $\begin{array}{l}\text { In case of one measurement } \\
\text { available for a species, a } \\
\text { triangular distribution of the } \\
\text { NOEC is built. } \\
\text { In case of two measurements } \\
\text { available for one species, a } \\
\text { trapezoidal distribution is built. } \\
\text { In case of three or more } \\
\text { measurements available for one } \\
\text { species, a complex distribution } \\
\text { is built. } \\
\text { The fact that an identical } \\
\text { NOEC can occur several times } \\
\text { for one species is considered. }\end{array}$ \\
\hline $\begin{array}{l}\text { 3. Derive the } \\
\operatorname{PSSD}(\mathrm{s})\end{array}$ & $\begin{array}{l}\text { A single PSSD is sampled from } \\
\text { all species-specific } \\
\text { distributions. }\end{array}$ & $\begin{array}{l}\text { Multiple PSSDs are } \\
\text { extracted from the species- } \\
\text { specific probability } \\
\text { distributions. }\end{array}$ \\
\hline $\begin{array}{l}\text { 4. Calculate the } \\
\text { PNEC } \\
\text { probability } \\
\text { distribution }\end{array}$ & $\begin{array}{l}\text { The PNEC is calculated as the } \\
\text { fifth percentile of the PSSD. A } \\
\text { probability distribution is built } \\
\text { from a confidence interval. }\end{array}$ & $\begin{array}{l}\text { The PNEC probability } \\
\text { distribution is derived } \\
\text { directly from the fifth } \\
\text { percentiles of all PSSDs. }\end{array}$ \\
\hline
\end{tabular}

This article is protected by copyright. All rights reserved. 
Table 5: Structures of the communities corresponding to all species for which data was collected. The typical structure is as reported by Forbes and Calow (2002).

\begin{tabular}{|l|c|c|c|}
\hline & CNT & Nano-Ag & Typical structure \\
\hline Primary producers & $50 \%$ & $38 \%$ & $65 \%$ \\
\hline Herbivores & $20 \%$ & $38 \%$ & $25 \%$ \\
\hline Carnivores & $30 \%$ & $24 \%$ & $10 \%$ \\
\hline
\end{tabular}

Table 6: Statistical values of the PNECs obtained with different methods and datasets. Q5, Q25, Q75 and Q95 correspond to the $5^{\text {th }}, 25^{\text {th }}, 75^{\text {th }}$ and $95^{\text {th }}$ percentiles.

\begin{tabular}{|c|c|c|c|c|c|c|}
\hline \multicolumn{7}{|c|}{$\mathrm{CNT}\left(\mu \mathrm{g} . \mathrm{L}^{-1}\right)$} \\
\hline Dataset & Q5 & Q25 & median & mean & Q75 & Q95 \\
\hline Base dataset & 13 & 32 & 61 & 86 & 111 & 257 \\
\hline $\begin{array}{l}\text { Typical commu- } \\
\text { nity }\end{array}$ & 13 & 32 & 61 & 86 & 111 & 255 \\
\hline Chronic dataset & N.A. & N.A. & N.A. & 125 & N.A. & N.A. \\
\hline Acute dataset & N.A. & N.A. & N.A. & 1'551 & N.A. & N.A. \\
\hline \multicolumn{7}{|c|}{ Nano-Ag (ng.L $\left.{ }^{-1}\right)$} \\
\hline Dataset & Q5 & Q25 & median & mean & Q75 & Q95 \\
\hline Base dataset & 7 & 11 & 31 & 77 & 126 & 257 \\
\hline $\begin{array}{l}\text { Typical commu- } \\
\text { nity }\end{array}$ & 3 & 6 & 9 & 57 & 20 & 337 \\
\hline Chronic dataset & 606 & 1’082 & 1'562 & 1'606 & 2’081 & 2’785 \\
\hline Acute dataset & 227 & 1’366 & 2’879 & 2’823 & 4’273 & 5’785 \\
\hline
\end{tabular}

\footnotetext{
${ }^{\mathrm{i}}$ For Lemna sp., the exposure duration distinguishing acute from chronic tests was taken as 2.5 days, which is the frond number doubling time required in OECD Test Guideline 221. This guideline suggests using an exposure duration of 7 days. The studies included in this work used exposure durations of 7 or 14 days, so the corresponding data points were all considered chronic.
}

This article is protected by copyright. All rights reserved. 
ii The US EPA published a testing guideline specific to C. dubia, according to which chronic toxicity can be tested with exposure durations of 7 days. This threshold was therefore considered for this specific crustacean species.

This article is protected by copyright. All rights reserved. 